\title{
Cefotaxime-induced Stevens-Johnson syndrome
}

\author{
Sandeep Lahiry ${ }^{1}$, Dibyendu Mukherjee ${ }^{2}$ \\ ${ }^{1}$ Post Graduate Trainee, Department of Pharmacology, Institute of Post Graduate Medical Education and Research, \\ ${ }^{2}$ Assistant Professor, Department of Medicine \& Specialist Rheumatology Clinic, KPC Medical College, Kolkata, \\ West Bengal, India
}

Stevens-Johnson syndrome (SJS) and Toxic Epidermal Necrolysis (TEN) are severe cutaneous immune-complex mediated hypersensitivity reactions. Drugs, especially sulfa drugs, antiepileptics, and antibiotics like cephalosporins, are the most common causes. Maculopapular lesions rapidly spread and coalesce, leading to epidermal blistering, necrosis, and sloughing. Diagnosis is usually obvious by appearance of initial lesions and clinical syndrome. Treatment is supportive care; cyclosporine, plasma exchange or IVIG, and early pulse corticosteroid therapy have been used. Mortality can be as high as $7.5 \%$ in children and 20 to $25 \%$ in adults but tends to be lower with early treatment. Here, we present a case of a 26 year old female who presented with extensive dermal lesions and ocular findings including periorbital skin scarring, conjunctivitis with corneal erosions, as well as fever and prostration, soon after the administration of cefotaxime. Epidermal detachment was observed in $<10 \%$ of her body surface. This presentation is consistent with the features of SJS. Resolution of the clinical manifestations was observed after discontinuation of the drug: all other drugs, infections, or immunologic disorders that could have caused this syndrome were carefully excluded. An objective causality assessment revealed that SJS was possibly associated with the use of cefotaxime.

Key words: Stevens-Johnson syndrome, Erythema multiforme, Toxic epidermal Necrolysis, Cefotaxime

\section{INTRODUCTION}

Stevens-Johnson syndrome (SJS) is a form Toxic Epidermal Necrolysis (TEN), a life-threatening skin condition, in which cell death causes the epidermis to separate from the dermis. ${ }^{1}$ The syndrome is thought to be a hypersensitivity complex that affects the skin and the mucous membranes. ${ }^{2}$ The immune reaction can be triggered by drugs or infections. ${ }^{3}$ Genetic factors are associated with a predisposition to SJS. ${ }^{4}$ The cause of drug induced SJS is unknown in one-quarter to one-half of cases. ${ }^{4}$

Although use of cephalosporins (mainly cephalexin) has been associated with development of SJS, cefotaxime, a third-generation cephalosporin, has been suspected of being associated with SJS in 2 reports only. ${ }^{5,6}$ We describe the case of a 26-year-old woman who developed SJS temporally related to cefotaxime administration.

\section{CASE REPORT}

A 25 year old lady had consulted a dentist for a tooth-ache. She was therefore prescribed antibiotics and painkillers, namely cefotaxime $1 \mathrm{gm}$ thrice daily and FDC of paracetamol $(500 \mathrm{mg})$ and tramadol $(50 \mathrm{mg})$ thrice daily. She had never received cefotaxime before. There was no history of any autoimmune disease and patient had denied the use of over-the-counter medications. There was no history of drug allergy or any recent immunization.

Three days later, she was febrile; and had started to develop a systemic maculopapular rash along with erosive lesions

Address for correspondence:

Dr. Sandeep Lahiry, 244 B A.J.C Bose Road, Department of Pharmacology, Institute of Post Graduate

Medical Education and Research, Kolkata, West Bengal - 700 020, India

E-mail: sndplry@gmail.com, Phone: +91-9432879503 
of the skin and oral mucus membrane. The lesions were predominantly around the eyes, including the eyelids, oropharyngeal mucus membranes, upper abdomen, chest and back (Figures 1 and 2). The rashes were accompanied with high grade fever (102 degrees F), arthralgias, malaise, Dysphagia and altered bowel habits. The patient was transferred to our setting for intensive monitoring.

On admission, she was febrile. Her vitals were: BP 90/60 mm Hg, RR 26/min, HR 110 beats/min, oxygen saturation $98 \%$ in room air. She had developed extensive blisters with positive Nikolsky's sign on all her skin and mucus membranes. Epidermal detachment was observed in $<10 \%$ of her body surface. There was periorbital skin scarring, conjunctivitis with corneal erosions. Skin biopsy was not taken.

Blood investigations revealed eosinophilia (1020 cells $\left./ \mathrm{mm}^{3}\right)$, elevated ESR (42: $1^{\text {st }}$ hour). Liver function test revealed transaminitis (mild). Renal function test were normal,

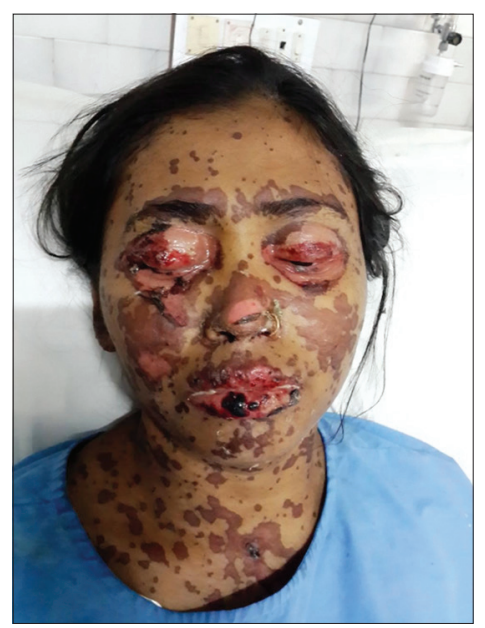

Figure 1: Dermal erosions involving periorbital, lips and adjoining facial area

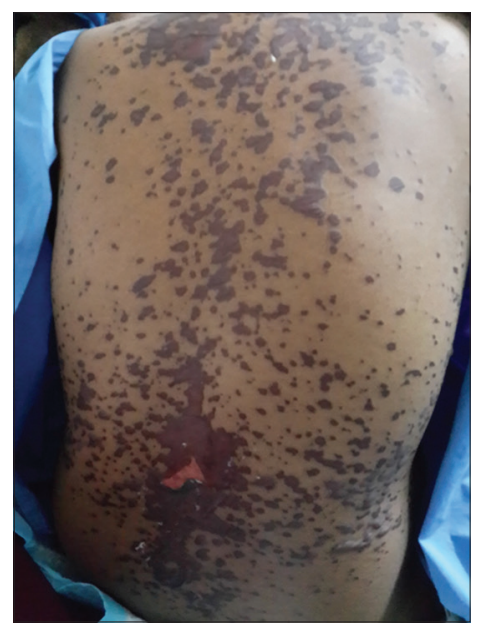

Figure 2: Extensive skin lesion in the back though routine examination showed mild proteinuria (800 mg/day) and presence of red blood cells (12-14 per hpf), white blood cells (1-2 cells/hpf), eosinophills and granular casts in the urine sediment.

Cefotaxime was stopped, and substituted with amoxicillinclavulinic acid. The patient received a short course corticosteroid treatment (methylprednisolone $80 \mathrm{mg}$ /day for 7 days). 10 days later, there was marked improvement in her condition. Concurrent medications were gradually started during hospitalization without any problem. She was finally discharged on day $14^{\text {th }}$ and remained in good health at $28^{\text {th }}$ day follow-up.

\section{DISCUSSION}

Steven-Johnson syndrome (SJS) is an immune-complex mediated hypersensitivity reaction involving skin and mucus membrane. ${ }^{7}$ It is an acute life-threatening condition, often caused by certain infections or drugs. The severity spectrum is based on the degree of body surface area detachment (BSA):

1. SJS: A minor form of Toxic Epidermal Necrolysis (TEN), with $<10 \%$ BSA detachment

2. Overlapping SJS/TEN: BSA detachment 10-30\%

3. TEN: BSA detachment $>30 \%$

Patients of SJS typically present with prodormal symptoms of productive cough, headache, malaise and arthralgia. Rash is typically symmetrical, involving mostly face, neck and chest. The cutaneous lesions are burning in nature, developing into papules, vesicles, bullae, urticarial plaques or confluent erythema. ${ }^{8}$ The lesion's core may be vesicular, purpuric or necrotic, surrounded by macular erythema, but later become bullous and rupture with denudation of skin and increased susceptibility to infection to follow. Urticarial lesions are typically not pruritic. The rashes may involve palms, soles, limbs and trunk. Mucus membranes may be involved with varying degree of erythema, edema, sloughing, ulceration or even necrosis. Involvement of mucus membrane and absence of pathognomic target lesions are keys to differentiate SJS from Erythema Multiforme. $^{9}$

Ocular signs like blepharitis, periocular edema, trichiasis, conjuctival shrinkage, foreshortening of fornices, symblepharon. Slit-lamp examination of cornea and conjunctiva may reveal superficial punctuate keratitis, stromal ulcers, stromal opacity, neovascularisation or even perforation. ${ }^{10}$

Skin biopsy may help differentiate the condition from other intraepidermal bullous diseases not related to drug 
therapy. Histopathological examination may reveal changes in dermo-epidermal junction ranging from vacuolar alteration to subepidermal blisters, perivascular dermal infiltrates, keratinocyte apoptosis and epidermal infiltration of CD8-T cells. Immunohistology of conjuctival vessels reveal numerous HLA-DR positive cells in substansia propria, vessel wall and epithelium. ${ }^{11}$

Dehydration and secondary infection are the main complications of SJS. ${ }^{12}$ Management is symptomatic, with special attention to airway and hemodynamic stability, wound care and pain alleviation measures. ${ }^{13}$ Recognition and cessation of responsible drug or treatment of precipitating infection is the mainstay. Topical anesthetics, mouthwashes are prescribed for painful oral lesions. Denuded skin areas are managed with compresses of saline. Tetanus toxoid prophylaxis and antibiotic coverage is usually recommended. Extensive debridement of non-viable skin followed by dressing is recommended. ${ }^{14}$ Although our patient was given corticosteroids, the value of systemic steroids in this syndrome is controversial. ${ }^{15}$

Ocular complication can be mitigated with aggressive usage of lubrications. Long standing cases often require topical steroids to counter ensuing inflammation and cicatricial changes along with removal of keratinized plaques or superficial keratectomy of keratinized ocular surfaces. Newer modalities under research include limb stem cells transplantation, amniotic grafting etc.

More than 100 drugs have been implicated as causes of SJS, with sulfonamides, antiepileptic agents, oxicam derivatives, allopurinol, chlormezanone, and steroids being the most commonly listed ones. ${ }^{16}$ Cephalosporin- induced allergic skin reactions are usually mild. In our case, the patient was on many drugs, but temporal association with the administration of oral cefotaxime and pathogenesis of SJS was concluded as disease worsening was prevented with the drug withdrawal.

\section{CONCLUSION}

The diagnosis of a possible cefotaxime-induced SJS remains presumptive or probable, but may be considered 'possible' in our case. Since the condition may have an immunological basis, additional cases and supportive data may be needed to establish a definite causal relationship.

\section{ACKNOWLEDGEMENT}

We are thankful to the faculty members of the Department of Pharmacology, Institute of Post Graduate Medical Education and Research Kolkata \& Department of
Medicine, KPC Medical College \& Hospital, Kolkata, for their invaluable support in letting us carry out the project work.

\section{REFERENCES}

1. Schwartz RA, McDonough PH and Lee BW. Toxic epidermal necrolysis: Part II. Prognosis, sequelae, diagnosis, differential diagnosis, prevention, and treatment. J Am Acad Dermatol 2013; 69(2):187.

2. Kohanim S, Palioura S, Saeed HN, Akpek EK, Amescua G, Basu S, et al. Stevens-Johnson Syndrome/Toxic Epidermal Necrolysis--A Comprehensive Review and Guide to Therapy. I. Systemic Disease. Ocul Surf 2016; 14(1):2-19.

3. Tan SK and Tay YK. Profile and pattern of Stevens-Johnson syndrome and Toxic Epidermal Necrolysis in a general hospital in Singapore: Treatment outcomes. Acta Derm Venereol 2012; 92(1):62-66.

4. Patel PP, Gandhi AM, Desai CK, Desai MK and RK Dikshit. An analysis of drug-induced Stevens-Johnson syndrome. Indian J Med Res 2012; 136(6): 1051-1053.

5. Liberopoulos EN, Liamis GL and Elisaf MS. Possible cefotaximeinduced Stevens-Johnson syndrome. Ann Pharmacother 2003; 37(6):812-814.

6. Ravishankar $\mathrm{M}$ and Shravani MN. Cefotaxime-induced Stevens-Johnson syndrome: a case report. 2015; Int J Basic Clin Pharmacol 2015; 4(1): 168-171.

7. Leaute-Labreze C, Lamireau T, Chawki D, Maleville J and Taieb A. Diagnosis, classification, and management of erythema multiforme and Stevens-Johnson syndrome. Arch Dis Child 2000; 83:347-352.

8. Rzany B, Hering O, Mockenhaupt M, Schröder W, Goerttler E, Ring $J$, et al. Histopathological and epidemiological characteristics of patients with erythema exudative multiforme major, Stevens-Johnson syndrome and toxic epidermal necrolysis. Br J Dermatol. 1996; 135(1):6-11.

9. Huff JC, Weston WL and Tonnesen MG. Erythema multiforme: A critical review of characteristics, diagnostic criteria, and causes. J Am Acad Dermatol 1983; 8(6):763-775.

10. Power WJ, Ghoraishi M, Merayo-Lloves J, Neves RA and Foster CS. Analysis of the acute ophthalmic manifestations of the erythema multiforme/Stevens-Johnson syndrome/toxic epidermal necrolysis disease spectrum. Ophthalmology 1995; 102(11):1669-1676.

11. Rzany B, Hering O, Mockenhaupt M, Schopf E, Ring J, Goerttler E, et al. Histopathological and epidemiological characteristics of patients with erythema exudativum multiforme major, Stevens-Johnson syndrome and toxic epidermal necrolysis. British Journal of Dermatology 1996;135(1): 6-11.

12. Auquier-Dunant A, Mockenhaupt M, Naldi L, Correia O, Schröder W, Roujeau JC, et al. Correlations between clinical patterns and causes of erythema multiforme major, StevensJohnson syndrome, and toxic epidermal necrolysis: results of an international prospective study. Arch Dermatol 2002; 138(8):1019-1024.

13. Ghislain PD and Roujeau JC. Treatment of severe drug reactions: Stevens-Johnson syndrome, toxic epidermal necrolysis and hypersensitivity syndrome. Dermatol Online J 2002; 8(1):5.

14. Fromowitz JS, Ramos-Caro FA and Flowers FP. Practical guidelines for the management of toxic epidermal necrolysis and Stevens-Johnson syndrome. Int J Dermatol 2007; 46(10):1092-1094. 
15. Letko E, Papaliodis DN, Papaliodis GN, Daoud YJ, Ahmed AR and Foster CS. Stevens-Johnson syndrome and toxic epidermal necrolysis: a review of the literature. Ann Allergy Asthma Immunol 2005; 94(4):419-436.
16. Roujeau JC, Kelly JP, Naldi L, Rzany B, Stern RS, Anderson T, et al. Medication use and the risk of Stevens-Johnson syndrome or toxic epidermal necrolysis. N Engl J Med 1995; 333(24):16001607.

Authors Contribution:

SL - Conceptualized study, literature search, prepared first draft of manuscript and critical revision of the manuscript; DM - Review of study.

Source of Support: Nil, Conflict of Interest: None declared. 